\title{
Metodologia de análise tarifária baseada no consumo de energia elétrica
}

Ao fazer uma pequena analise de qual é a opinião da população com relação aos preços pagos nas contas de energia elétrica é possível perceber uma indignação da maioria dos consumidores. Hoje em dia tem algumas temporadas em que estas reclamações são mais evidenciadas, isto se dá devido os aumentos que tem de acordo com o clima da região, pois acaba influenciando o nível de água dos reservatórios. Com isso este estudo analisa como é realizada essa cobrança aos consumidores, sendo identificada por uma tabela que mostra todos os serviços prestados. O parâmetro utilizado foi o consumo médio e as informações fornecidas pela Agência Nacional de Energia Elétrica (ANEEL), devido ser uma agência em que toda a administração é realizada por ela, desde a produção até a comercialização. Para a obtenção dos valores de alguns serviços realizados foi necessário buscar informações na Energisa, concessionária local no estado do Tocantins, pois é ela a empresa responsável pela distribuição de energia elétrica na região que foi analisada.

Palavras-chave: Energia elétrica; Consumo médio; Consumidores.

\section{Methodology of tariff analysis based on electric power consumption}

By doing a little analysis of what is the opinion of the population regarding the prices paid on the electricity bills, it is possible to perceive the indignation of most consumers. Nowadays there are some seasons when these complaints are more evident, this is due to the increases that have according to the climate of the region, as it ends up influencing the water level of the reservoirs. Thus, this study analyzes how this collection is made to consumers, being identified by a table that shows all services provided. The parameter used was the average consumption and information provided by the National Electric Energy Agency (ANEEL), due to being an agency in which all administration is performed by it, from production to commercialization. In order to obtain the values of some services performed it was necessary to seek information from Energisa, a local concessionaire in the state of Tocantins, as it is the company responsible for the distribution of electricity in the region that was analyzed.

Keywords: Electricity; Average consumption; Consumers.

Topic: Engenharia Civil

Reviewed anonymously in the process of blind peer.
Received: 21/05/2019

Approved: 11/08/2019
Laressa Moreira de Souza (iD)

Instituto Tocantinense Presidente Antonio Carlos , Brasil

http://lattes.cnpq.br/6656923908702102

http://orcid.org/0000-0001-6514-1160

laressa.m96@gmail.com
Referencing this:

SOUZA, L. M.. Metodologia de análise tarifária baseada no consumo de energia elétrica. Technology Science, v.1, n.2, p.7-14, 2019. DOI: http://doi.org/10.6008/CBPC2674-6425.2019.002.0002 


\section{INTRODUÇÃO}

Por volta de 1979 o governo federal comprou a empresa Light, sendo a empresa responsável pelo fornecimento de energia elétrica na época, a empresa em questão foi a principal investidora para a construção de usinas hidrelétricas que acabou contribuindo muito para o processo de industrialização do Brasil, a qual atualmente possui uma parcela maior de consumo de usinas hidrelétricas do que as demais fontes de energia existente (CEMIG, 2019).

Devido a energia consumida ter uma grande importância para o funcionamento do dia a dia de cada pessoa torna necessário um melhor conhecimento de como funciona a cobrança de energia. De acordo com Eletrobrás (2011), existem diversos tipos de tarifas onde dependendo do consumo e da hora que é consumida, torna possível uma redução no custo cobrado pela concessionaria local.

Para a geração de energia elétrica são realizadas diversas etapas, onde o primeiro passo é obter uma força que consiga girar as turbinas nas usinas hidrelétricas, no Brasil existe um desnível considerável, para utilizar isso a favor é necessário represar o rio para que então a própria força da água consiga movimentar as hélices da turbina (BRUNO, 2018). No interior da barragem é instalado dutos com uma certa inclinação o qual direcionam a água por um caminho até chegar na hélice como mostra a figura 1, quando a água exerce a força sobre a hélice fazendo o sistema girar para movimentar o eixo do gerador (BRUNO, 2018).

Próximo ao gerador é instalado um transformador que tem a função de transformar energia mecânica em energia elétrica e posteriormente enviar por meio de cabos gerando uma linha de transmissão. Toda a água utilizada nesse processo e devolvida ao rio novamente, com isso a energia hidrelétrica é considerada como uma fonte de energia limpa e renovável (ALIANÇA, 2019).

\section{METODOLOGIA}

O presente trabalho e composto por uma análise comparativa entre a tarifa branca e a tarifa de classe $B$, as quais são destinadas para consumidores de baixa tensão, onde com base na média do consumo de energia, identificar qual adesão de tarifa torna o custo mais econômico, para o respectivo trabalho foi retirado dados da composição de tarifas na base de dados da Energisa, concessionária local do estado do Tocantins.

Esse presente estudo pretende ajudar a população do estado a encontrar qual a melhor tarifa de energia para consumidores de baixa tensão, o qual foi formulada uma planilha no Excel na qual o consumo médio e a demanda utilizada proporciona um comparativo entre dois tipos de tarifas a serem contratadas e assim proporcionar o consumidor um novo conhecimento para que faça a escolha da tarifa mais adequada ao modo que realiza o consumo de energia elétrica.

De acordo com informações de Fugimoto (2010), o que mantem o serviço de fornecimento de energia funcionando é o equilíbrio entre a parte econômica e financeira, onde a parcela A representa os custos exógenos da distribuidora, conhecido como um custo não gerenciável, já a parcela B é o custo gerado com o controle de distribuição também identificado como custo gerenciáveis. 
De acordo com a Eletrobrás (2011), o manual de tarifação relata que o consumo de energia é a quantidade de potência consumida por um determinado intervalo de tempo, sendo estabelecido que sua unidade de medida é em quilowatt-hora (kWh). O consumo é determinado pelo resultado de $\frac{T * P}{1000}$ onde o tempo e multiplicado pela demanda, já para obter o valor cobrado pelo consumo é só multiplicar o número do consumo pelo valor estabelecido a cada unidade de KWh de acordo com a Energisa.

As bandeiras tarifárias são três, identificadas como bandeira verde, amarela e vermelha, similar as cores utilizadas como sinalização de trânsito, assim como os sinais de trânsito as bandeiras também estão presentes como uma alerta pois cada uma tem forma diferente de ser cobrada (ANEEL, 2019). O valor determinado para cada bandeira está relacionado ao nível de água do reservatório da usina hidrelétrica, um fator que influencia diretamente é o clima de cada região devido todos os anos ocorrer mudanças nos tempos chuvosos, pois nem todos os anos chovem o mesmo que o ano anterior podendo variar tanto para mais quanto para menos (ENERGISA, 2019).

\section{Tarifa Branca}

De acordo com a ANEEL (2019), informa que a tarifa branca já estar à disposição desde o primeiro dia do ano de 2019, sendo indicada para as unidades que utilizam atendimento por baixa tensão. Nas residências existem os eletrodomésticos que consomem mais energia que os outros, um exemplo a ser mencionado é o chuveiro elétrico e equipamentos utilizados para refrescar o ambiente, caso não seja possível desviar o horário de consumo desses equipamentos que tem alta demanda é indicado que não realize a mudança de tarifa, pois em vez de ter uma economia terá um aumento na sua conta (ANEEL, 2019).

Para a tarifa branca a preciso conhecer o que é o horário de ponta e de ponta fora, pois são essenciais para estimar o valor cobrado. O horário de ponta trata-se de um consumo dentro de um período de 3 horas consecutivas, mas excluindo os finais de semana e feriados nacionais. Esse horário é definido pela concessionária local, isso ocorre porque valores diferenciados podem ser cobrados de acordo com a modalidade da tarifa, devido ser o momento de maior demanda de energia. Energisa (2019) demonstra que:

A Tarifa Branca é um incentivo para que alguns consumidores desloquem o consumo dos períodos de ponta para aqueles em que a rede de distribuição de energia elétrica tem capacidade adicional de atendimento, ou seja, quando o consumo é menor, reduzindo a necessidade de investimentos adicionais no sistema e contribuindo para a modicidade das tarifas.

De acordo com a Energisa (2019), o intervalo estabelecido como o horário de ponta fora é das 19 horas até as 21:59 do mesmo dia, durante esse intervalo é considerado o horário intermediário que considera uma hora antes de começar o horário de ponta e uma hora depois. Ainda de acordo com informações fornecidas pela Eletrobrás (2011), o horário de ponta fora equivale as 21 horas restantes de um dia referente ao horário de ponta, sendo o tempo em que ocorre a menor demanda de energia.

\section{Tarifa Convencional}

Na tarifa convencional é cobrado um único valor para o emprego de energia utilizada sem nenhuma 
diferença independente no horário e dia que está sendo consumida, no caso da tarifa branca já não é levado em conta as mesmas condições. Segundo Lamas (2010), "esta estrutura tarifária é caracterizada pela aplicação de tarifa de consumo de energia e demanda de potência, aplicadas independentes das horas de utilização do dia e doa períodos do ano [...]".

\section{Horo-Sazonal Verde}

Para o Horo-Sazonal Verde só é possível para as estruturas tarifárias no qual as unidades consumidoras fazem parte do grupo A, no entanto, exige que seja realizado um contrato entre cliente e concessionária para assim estabelecer qual será a demanda determinada por ambos, independente do horário que seja utilizada (ELETROBRÁs, 2011). ANEEL (2019) mostra que:

[...]Tarifa Verde: modalidade estruturada para aplicação de tarifas diferenciadas de consumo de energia elétrica de acordo com as horas de utilização do dia e os períodos do ano, bem como de uma única tarifa de demanda de potência.

\section{Horo-Sazonal Azul}

No Horo-Sazonal Azul é necessário a realização de um contrato entre cliente e concessionária, no entanto, a fatura de energia elétrica para esses consumidores permitiu que seja escolhida mais de uma tarifa a qual pode estar ocorrendo variações de acordo com período de estiagem e cheia (ELETROBRÁS, 2011). ANEEL (2019) mostra que:

[...]Tarifa Azul: modalidade estruturada para aplicação de tarifas diferenciadas de consumo de energia elétrica de acordo com as horas de utilização do dia e os períodos do ano, bem como de tarifas diferenciadas de demanda de potência de acordo com as horas de utilização do dia[...].

\section{Impostos e Tributos}

Segundo informações da ANEEL (2019), determina que os custos de distribuição devem ser analisados de acordo com as definições de todas as tarifas, considerando a geração de energia, o transporte e os encargos setoriais. De acordo com a Energisa (2019), o Programa de Integração Social (PIS) e a Contribuição para o Financiamento da Seguridade Social (COFINS) são valores arrecadados pela União com base em um programa social do Governo Federal.

Quanto ao valor específico de cada um, tais como PIS e COFINS são determinados de maneiras similares, onde o valor do PIS é encontrado pela multiplicação da porcentagem da alíquota (1,65\%) pela base de cálculos do imposto em questão, para conseguir o valor do COFINS é só multiplicar a alíquota $(7,6 \%)$ pela base de cálculo.

Para a comercialização de mercadoria é cobrado o ICMS, isto também ocorre na fatura de energia, a alíquota no estado do Tocantins é de $25 \%$ mais em alguns casos são insetos tais como no caso de estar na classe de iluminação pública, residencial baixa renda e suprimento. Para a realização dos cálculos da tabela que demostra o provável valor cobrado pelo fornecimento de energia elétrica é necessário saber de que forma essa equação e composta. No primeiro momento será definida as grandezas que são essenciais para 
os cálculos, tais como o horário de ponta e ponta fora, demanda, ajustes das bandeiras referente ao mês desejável e o consumo médio, após essas definições foram definidas as unidades de medidas dos valores que compõem os cálculos.

\section{RESULTADOS}

Foi iniciado uma primeira observação para a tarifa convencional B, a qual e destinada a consumidores de baixa tensão, nesse estudo não foi levado em consideração os consumidores cadastrados como baixa renda devido não ter a possibilidade de fazer mudança para uma outra tarifa e também por já ter um benefício de pagar um valor abaixo que os demais clientes. Nessa primeira analise apresentada pela tabela 1 é possível perceber o valor cobrado por cada item da composição da cobrança realizada pela Energisa para quando o consumo e de $70 \mathrm{KWh}$, onde o valor apresentado é uma estimativa por não ser levado em consideração a cobrança de iluminação pública.

Tabela 1: Detalhe do modo como e cobrado a tarifa Convencional B, para um consumo de 70 KWh.

\begin{tabular}{|c|c|c|}
\hline Grandezas & Valor Unit. (R\$) & Valor Total (R\$) \\
\hline Consumo & 0,51007 & 35,70 \\
\hline Iluminação Pública & 0,00 & 0,00 \\
\hline PIS & $0,77 \%$ & 0,39 \\
\hline COFINS & $3,54 \%$ & 1,79 \\
\hline ICMS & $25,00 \%$ & 12,63 \\
\hline \multicolumn{2}{|l|}{ Total da Fatura: } & 50,51 \\
\hline
\end{tabular}

Para a mesma tarifa mais com o um consumo de $260 \mathrm{KWh}$, obteve se outros valores como mostra a tabela 2, isso ocorre porque a base de dado de entrada é a quantidade consumida e quando a aquisição é alterada o valor também sofre um reajuste.

Tabela 2: Detalhe do modo como e cobrado a tarifa Convencional B, para um consumo de $260 \mathrm{KWh}$.

\begin{tabular}{|l|r|r|}
\hline \multicolumn{1}{|c|}{ Grandezas } & Valor U nit. (R\$) & Valor Total (R\$) \\
\hline Consumo & 0,51007 & 132,62 \\
\hline lluminação Pública & 0,00 & 0,00 \\
\hline PIS & $0,77 \%$ & 1,45 \\
\hline COFINS & $3,54 \%$ & 6,64 \\
\hline ICMS & $25,00 \%$ & 46,90 \\
\hline \multicolumn{2}{|l|}{ Total da Fatura: } & \\
\hline
\end{tabular}

Assim como na tarifa convencional B a tarifa branca também é calculada de acordo com o consumo realizado, mais com uma pequena diferença sobre seus horários de utilização, para um melhor entendimento a tabela 3 traz o valor quando e realizado um consumo de $260 \mathrm{KWh}$ somente no horário de fora ponta, o qual possui um valor bem abaixo do cobrado na tarifa convencional B.

Tabela 3: Detalhe do modo como e cobrado a tarifa Branca, para um consumo de $260 \mathrm{KWh}$.

\begin{tabular}{||l|r|r|}
\hline \multicolumn{1}{|c|}{ Grandezas } & Valor Unit. (R\$) & Valor Total (R\$) \\
\hline Consumo Fora Ponta & 0,40679 & 105,77 \\
\hline Consumo Ponta & 1,14354 & 0,00 \\
\hline Iluminação Pública & 0,00 & 0,00 \\
\hline PIS & $0,77 \%$ & 1,15 \\
\hline COFINS & $3,54 \%$ & 5,29 \\
\hline ICMS & $25,00 \%$ & 37,40 \\
\hline Total da Fatura: & & $\mathbf{1 4 9 , 6 2}$ \\
\hline \hline
\end{tabular}

Quando se trata da tarifa branca existe um modificação, pois é levado em consideração a hora em 
ocorreu o consumo, isso porque os valores para horário de ponta e de fora ponta sofrem uma diferença a qual e perceptiva ao observar o valor final da fatura estimada como mostra na tabela 4, para um consumo de 260 KWH onde 200 está no horário de fora ponta é 60 no horário de ponta.

Tabela 4: Detalhe do modo como e cobrado a tarifa Branca, para um consumo de $260 \mathrm{KWh}$, com consumos alternados em horário de ponta e fora ponta.

\begin{tabular}{||l|r|r||}
\hline \multicolumn{1}{|c|}{ Grandezas } & Valor Unit. (R\$) & Valor Total (R\$) \\
\hline Consumo Fora Ponta & 0,40679 & 81,36 \\
\hline Consumo Ponta & 1,14354 & 68,61 \\
\hline lluminação Pública & 0,00 & 0,00 \\
\hline PIS & $0,77 \%$ & 2,16 \\
\hline COFINS & $3,54 \%$ & 9,93 \\
\hline ICMS & $25,00 \%$ & 70,19 \\
\hline Total da Fatura: & $\mathbf{2 8 0 , 7 6}$ \\
\hline
\end{tabular}

\section{DISCUSSÃO}

Diante o presente trabalho é possível entender que não somente o valor da tarifa contratada multiplicada pela cobrança de cada KWh influência o resultado final do valor pago, pois a maneira como é realizado esse consumo também é um fator muito importante. E possível perceber que pouco coisa de diferença da maneira como se consome energia elétrica acaba sofrendo uma modificação muito intensa.

Quando analisamos o valor de 260 KWh para uma tarifa convencional de classe B obtém o valor de R\$ 187,60 aproximadamente, devido não levar em consideração a taxa de iluminação pública que também e cobrado junto ao consumo mensal nas contas de energia, nem o possível acréscimo das bandeiras tarifarias. Dependendo da situação climática em que se encontra o estado ocorre algumas alterações de valores, as quais são baseadas de acordo com o nível de água atual da reserva da usina hidrelétrica.

Já em outra analogia utilizamos o mesmo valor de 260 KWh de consumo para a tarifa branca obtém um estimativa de $\mathrm{R} \$ 149,62$. Dessa forma logo dá a entender que a tarifa branca torna bem mais econômica que a convencional classe $B$, mais muito cuidado, pois não e tão simples com parece, essa economia só é possível quando o cliente consegue desviar toda a utilização do horário de ponta para o horário fora ponta, o qual possui um valor bem abaixo que o convencional.

Em casos que o consumo da tarifa branca se divide em consumos de horários de fora ponta e horário de ponta os valores já não proporcionaliza esse mesmo entendimento de viabilidade. No estudo apresentado na tabela 4, onde o consumo com valor igual de $260 \mathrm{KWh}$, mais desta vez o consumo está dividido em horários diferentes, ponta e fora ponta, obtém o valor total de aproximadamente $R \$ 280,76$. Assim é possível uma melhor percepção de que deve analisar primeiramente como o consumo e feito para então realizar a troca da tarifa.

A mudança da tarifa convencional B para a tarifa Branca só é possível caso o consumo seja maior que 250 KWh por mês e não ultrapassando o valor de $400 \mathrm{KWh}$, se o valor de consumo e menor que $250 \mathrm{KWh}$ então terá que permanecer na tarifa convencional. Quando a aquisição permite a transição de tarifa é preciso observar se seu consumo entre os horários das 19 às 22:59 horas são mínimos ou tem possibilidade de se reduzir, pois caso não tem a probabilidade de redução é indicado que não haja a troca, pois em vez de uma redução o que ocorre é um acréscimo de valor cobrado ao final do mês. 


\section{CONCLUSÕES}

Devido à grande indignação da população em relação ao valor pago mensalmente as contas de energia elétrica, foi então que uma curiosidade despertou o interesse sobre o assunto de forma a tentar esclarecer a população e assim despertar mudanças no consumo e na economia da conta. Para a elaboração da análise foi utilizado como base de dados apenas consumidores de baixa tensão, onde desenvolveu uma planilha que analisa como e realizada a cobrança pela utilização de energia. Informações sobre os valores cobrados por cada item foi muito importante para a elaboração além é claro das unidades de medidas as quais necessitava estar para conseguir converter o valor final, todos os valores de cada KWh foi retirado do site da Energisa, sendo a concessionária local do estado do Tocantins local de estudo do trabalho apresentado.

$\mathrm{Na}$ construção do estudo se determinou as unidades de medidas a qual utilizou isso porque teve que definir de que forma iria analisar, como foi o caso do presente trabalho que o valor de consumo utilizado é de acordo com um consumo gerado durante todo o mês, sendo o mesmo utilizado na cobrança mensal da concessionária para demais pessoas.

Por tanto a planilha proporcionou um novo conhecimento sobre uma comparação entre duas tarifas que está disponível para exploração dos consumidores de baixa tensão, os quais podem optar pela tarifa convencional B ou a tarifa Branca para consumo que esteja entre o intervalo de 250 a $400 \mathrm{KWh}$. Assim o consumidor entende melhor que para cada tarifa existe os seus benefícios mais também existe suas desvantagens, as quais devem ser bem analisadas para não cometer erro quando realizar a escolha de qual tarifa melhor se adequa ao seu dia a dia.

Caso o consumidor não consiga realizar a troca do horário ponta para o horário de fora ponta o indicado é que ele não faça a troca de tarifas, pois em vez de conseguir uma economia ele corre o risco de adquirir um acrescimento no final do mês. Mais se ao analisar o seu cotidiano e perceber que consegue realizar seu consumo somente em horário fora de ponta, dessa forma ele pode adquirir a mudança para a tarifa branca sem nenhum ressentimento, pois assim ele irá conseguir uma economia significativa ao final nos valores cobrados mensalmente pelos serviços prestados ao fornecimento de energia elétrica.

\section{REFERÊNCIAS}

ALIANÇA. Como funciona uma Usina Hidrelétrica. ALIANÇA, 2017.

ANEEL. Agência Nacional de Energia Elétrica. Cálculo tarifário e metodologias. Brasília: ANEEL, 2019.

ANEEL. Agência Nacional de Energia Elétrica. Gestão de recursos tarifários. Brasília: ANEEL, 2019.

ANEEL. Agência Nacional de Energia Elétrica. Tarifas consumidoras. Brasília: ANEEL, 2019.

BRUNO, D.C. N.. Os reflexos do sistema de bandeiras tarifárias em face do consumidor e concessionárias de energia elétrica. Tese (Mestrado Profissional em Direito de Empresa e Negócios) - Universidade do Vale do Rio dos
Sinos, São Leopoldo, 2018.

CEMIG. Companhia Energética de Minas Gerais. História da eletricidade no Brasil. Belo Horizonte: CEMIG, 2019.

ELETROBRÁS. Manual de Tarifação da Energia elétrica. Rio de Janeiro: ELETROBRÁS, 2011.

ENERGISA. Tarifa Branca beneficiará apenas clientes que consomem mais energia fora do horário de pico. Cataguases: ENERGISA, 2019.

ENERGISA. Tarifa social. Cataguases: ENERGISA, 2019.

ENERGISA. Tipos de tarifas. Cataguases: ENERGISA, 2019. 
ENERGISA. Tributos. Cataguases: ENERGISA, 2019.

FUGIMOTO, S. K.. Estrutura de tarifas de Energia Elétrica Análise crítica e proposições metodológicas. Tese

(Doutorado em Engenharia Elétrica) - Universidade de São Paulo, São Paulo, 2010.
LAMAS, E. S.. Metodologia para avaliação de alternativas de fornecimento de energia elétrica para consumidores do Grupo A. Dissertação (Mestrado em Engenharia Elétrica) Universidade Federal do Rio Grande do Sul, Porto Alegre, 2010.

A CBPC - Companhia Brasileira de Produção Científica (CNPJ: 11.221.422/0001-03) detém os direitos materiais desta publicação. Os direitos referem-se à publicação do trabalho em qualquer parte do mundo, incluindo os direitos às renovações, expansões e disseminações da contribuição, bem como outros direitos subsidiários. Todos os trabalhos publicados eletronicamente poderão posteriormente ser publicados em coletâneas impressas sob coordenação da Sapientiae Publishing, da Companhia Brasileira de Produção Científica e seus parceiros autorizados. Os (as) autores (as) preservam os direitos autorais, mas não têm permissão para a publicação da contribuição em outro meio, impresso ou digital, em português ou em tradução. 